\title{
Antioxidants: Environmental Stress Mitigating Metabolites
}

\author{
Yogendra K Meena ${ }^{1 *}$ and Nirmaljit Kaur ${ }^{2}$ \\ ${ }^{1}$ Department of Vegetable Science, Punjab Agricultural University, India \\ ${ }^{2}$ Department of Botany, Punjab Agricultural University, India
}

Submission: May 09, 2017; Published: June 14, 2017

"Corresponding author: Yogendra K Meena, Department of Vegetable Science, Punjab Agricultural University, Ludhiana-141004, India, Email: yogendra-coavs@pau.edu

\section{Review}

Environmental stresses due to cold, heat, salinity and drought adversely affect plant growth and productivity that trigger a series of morphological, physiological, biochemical and molecular changes in plants and eventually interrupt normal plant life cycle [1,2]. Most of the arable lands of the world that are exposed to abiotic stress conditions have an adverse impact on global vegetable production. These abiotic stress conditions decrease crop productivity upto 50-70\% [3]. Plants have evolved several metabolic cascades for their survival under stress [4].

Plant's response to stress is a complex phenotypic and physiological phenomena which is highly influenced by adverse environmental conditions. To enhance the food production in order to cope with increasing populations, crops are often grown under stressful environments which may result in lower yields. The key factors limiting yield and quality of crops are fluctuations in climatic conditions, such as stress, water stress, salt stress, etc. During winter season, its cold stress that adversely damages the vegetables production. In response to abiotic stress, several phenotypic symptoms such as stunted seedling, poor germination, reduced leaf expansion, yellowing of leaf (Chlorosis) and wilting occur, which sometimes results into tissue damage (necrosis) [5].

Reactive oxygen species (ROS) accumulate when plants encounter abiotic stress [6] and the overproduction of ROS under environmental stress can damage plant cells irreversibly by oxidation of cellular components, such as lipids, proteins, and DNA [6,7]. Therefore, excessive ROS must be scavenged as soon as possible. It is reported that ROS ca either be harmful when produced in excess, but beneficial at lower concentrations. ROS at low concentrations play an important role in regulating plant growth and development as well as in environmental acclimation [8]. Induction of the lipid peroxidation in plants due to excessive production of ROS is one major consequence of abiotic stress $[9,10]$. Under abiotic stress, imbalances in metabolic processes may result in increased accumulation of ROS, such as hydrogen peroxide, hydroxyl radical, superoxide and singlet oxygen $[11,12]$.

In order to scavenge ROS, plants have developed enzymatic and non-enzymatic antioxidant defense systems. Antioxidant enzymes viz., catalase, superoxide dismutase and ascorbate peroxidase quench ROS to protect plant cells. In addition to this, many non-enzymatic antioxidants like tocopherols, carotenoids, ascorbic acid have an important role to play in scavenging ROS. Multiple antioxidant enzymes are involved in the quenching of ROS. Superoxide dismutases (SOD) react with superoxide radical and produces hydrogen peroxide (H2O2) which is scavenged by peroxidases (POD) and catalases (CAT). CAT reacts with $\mathrm{H} 2 \mathrm{O} 2$ to produce oxygen and water. Among peroxidases, ascorbate peroxidases (APX) and glutathione peroxidase (GPX) use ascorbate and glutathione as electron donors, respectively and lead to $\mathrm{H} 2 \mathrm{O} 2$ detoxification in plants [13]. Exposure of plants to stress results in excessive production of ROS due to the restriction of carbon dioxide fixation in chloroplasts and mitochondrial electron transport chain [14].

The activity of antioxidant enzymes i.e., SOD, POX and CAT significantly increase in response to adverse environmental cues. Further, the maximum values of SOD, POX and CAT have been found in the plants exposed to the lowest temperature $\left(10 / 3^{\circ} \mathrm{C}\right)$, when plants encounter low temperature stress. With the decrease in the level of the temperature, the values of antioxidant enzymes increased [15]. At some stage of stress exposure, the usual consequence of nearly all stresses is that they result in an increased production of ROS, which may oxidize lipids, proteins and nucleic acids which results in deformity at the level of the cell [16]. When excessive ROS are produced, plants synthesize antioxidant enzymes (SOD, CAT and POX) and osmoprotectant (proline) that quench excess ROS. On the other hand, low temperature stress, or other environmental challenges exhibit enhanced production of ROS and malondialdehyde 
(MDA), used as an indicator of lipid peroxidation [17]. APX and CAT levels increased in roots of acclimated plants, whereas their levels remained unaffected in unstressed plants. Whereas, $\mathrm{H} 2 \mathrm{O} 2$ content in roots of acclimated plants was significantly lower than the control and non acclimated plants under low temperature stress in tomato [18].

Glycine betaine plays an important role as an compatible solute in plants experiencing in stress condition. Glycine betaine production in chloroplasts maintains the activation of Rubisco by sequestering Rubisco active near thylakoids and preventing its thermal inactivation [19]. For example, high levels of glycine betaine accumulation were reported in maize and sugarcane in response to high temperature, while in contrast, plant species such as rice, mustard and tobacco naturally do not produce glycine betaine under stress conditions [20,21].

Glutathione is a thiol which participates in redox regulation and plays a role in storage, transport, and regulation of metabolites. Furthermore, it is involved in the detoxification of reactive oxygen species. The involvement of glutathione in redox regulation plays a crucial role in withstanding environmental stresses. The application of buthionine sulfoximine, an enzyme inhibitor in the glutathione pathway, led to a $70 \%$ decrease of in vitro pollen germination in Arabidopsis [22] demonstrating the crucial role of glutathione in pollen germination. Glutathione reductase has been proclaimed to play a substantial role in the prevention of oxidative stress in plants under high and low temperature stresses. In plants, both oxidative stress and expression of antioxidant defense machinery have been observed as parallel with increasing or decreasing temperature, which was enunciated by many investigators $[23,24]$. The high catalase activity has the collateral effect on abiotic stress, i.e., it increases the rate of $\mathrm{H} 2 \mathrm{O} 2$ scavenging and enhances tolerance. Highest activity of catalase was recorded for stress tolerant genotypes. However, there was a reduction in the activity of guaiacol peroxidase in temperature stress [25].

\section{References}

1. Mahajan S, Tuteja N (2005) Cold, salinity and drought stresses: an overview. Arch Biochem Biophys 444(2): 139-158.

2. Ahmad P, MNV Prasad (2012) Abiotic stress responses in plants: metabolism, productivity and sustainability. New York, NY, USA.

3. Mittler R (2006) Abiotic stress, the field environment and stress combination. Trends Plant Sci 11(1): 15-19.

4. Dos Rei, SP, Lima AM De Souza CRB (2012) Recent molecular advances on downstream plant responses to abiotic stress. Int J Mol Sci 13: 8628-8647.

5. Ruelland E, Zachowski A (2010) How plants sense temperature. Environ Exp Bot 69: 225-232.

6. Miller G, Suzuki N, Ciftci-Yilmaz S, Mittler R (2010) Reactive oxygen species homeostasis and signalling during drought and salinity stresses. Plant Cell Environ 33(4): 453-467.

7. Apel K, Hirt H (2004) Reactive oxygen species: metabolism, oxidative stress, and signal transduction. Annu Rev Plant Biol 55: 373-399.
8. Quan LJ, Zhang B, Shi WW, Li HY (2008) Hydrogen peroxide in plants: a versatile molecule of reactive oxygen species network. J Integr Plant Biol 50: 2-18.

9. Ahmad P, Jaleel CA, Salem MA, Nabi G, Sharma S (2010) Roles of enzymatic and non-enzymatic antioxidants in plants during abiotic stress. Crit Rev Biotechnol 30(3): 161-75.

10. Gill SS, Tuteja N (2010) Reactive oxygen species and antioxidant machinery in abiotic stress tolerance in crop plants. Plant Physiol Biochem 48: 909-930.

11. Hung SH, Yu CW, Lin CH (2005) Hydrogen peroxide functions as a stress signal in plants. Bo Bull Academia Sinica 46: 1-10.

12. Goud PB, Kachole MS (2011) Effect of exogenous hydrogen peroxide on peroxidase and polyphenol oxidase activities in Cajanus cajan (L.) Millsp. detached leaves. Inter J Curr Res 3: 61-65.

13. Orabi SA, Dawood MG, Saleem SR (2015) Comparative study between the physiological role of hydrogen peroxide and salicylic acid in alleviating low temperature stress on tomato plants grown under sand- ponic culture. Sci Agric 9(1): 49-59.

14. Suzuki N, Mittler R (2006) Reactive oxygen species and temperature stresses: a delicate balance between signalling and destruction. Physiol Plant 126: 45-51.

15. Khan TA, Fariduddin Q, Yusuf M (2015) Lycopersicon esculentum under low temperature stress: an approach toward enhanced antioxidants and yield. Environ Sci Pollut Res 22(18): 14178-14788.

16. Sanita L, Gabbrielli R (1999) Response to cadmium in higher plants. Environ Exp Bot 41: 105-130.

17. Liu YJ, Han XM, Ren LL, Yang HL, Zeng QY (2013) Functional divergence of the glutathione S-transferase supergene family in Physcomitrella patens reveals complex patterns of large gene family evolution in land plants. Plant Physiol 161(2): 773-786.

18. Iseri OD, Korpe DA, Sahin FI, Haberal M (2013) Hydrogen peroxide pretreatment of roots enhanced oxidative stress response of tomato under cold stress. Acta Physiol Plant 35: 1905-1913.

19. Allakhverdiev SI, Kreslavski VD, Klimov VV, Los DA, Carpentier R, et al. (2008) Heat stress: an overview of molecular responses in photosynthesis. Photosynth Res 98: 541-550.

20. Quan RD, Shang M, Zhang H, Zhang J (2004) Improved chilling tolerance by transformation with bet A gene for the enhancement of glycinebetaine synthesis in maize. Plant Sci 166: 141-149.

21. Wahid A, Close TJ (2007) Expression of dehydrins under heat stress and their relationship with water relations of sugarcane leaves. Biol Plant 51(1): 104-109.

22. Zechmann B, Müller M, Zellnig G (2008) Modified levels of cysteine affect glutathione metabolism in plant cells. In Sulfur assimilation and abiotic stresses in plants Edited by Khan NA, Singh S, Umar S. The Netherlands, USA, pp. 193-206.

23. Panchuk II, Volkov RA, Schoffl F (2002) Heat stress and heat shock transcription factor dependent expression and activity of ascorbate peroxidase in Arabidopsis. Plant Physiol 129: 838-853.

24. Kochhar S, Kochhar VK (2005) Expression of antioxidant enzymes and heat shock proteins in relation to combine stress of cadmium and heat in Vigna mungo seedlings. Plant Sci 168: 921-929.

25. Rai N, Rai KK, Tiwar G and Singh PK (2015) Changes in free radical generation, metabolites and antioxidant defense machinery in hyacinth bean (Lablab purpureus L.) in response to high temperature stress. Acta Physiol Plant 37: 46. 


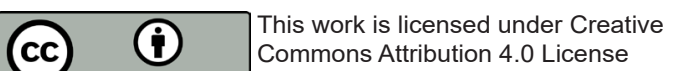
Commons Attribution 4.0 License DOI: $10.19080 /$ CTBEB.2017.05.555660

\section{Your next submission with Juniper Publishers} will reach you the below assets

- Quality Editorial service

- Swift Peer Review

- Reprints availability

- E-prints Service

- Manuscript Podcast for convenient understanding

- Global attainment for your research

- Manuscript accessibility in different formats ( Pdf, E-pub, Full Text, Audio)

- Unceasing customer service

Track the below URL for one-step submission https://juniperpublishers.com/online-submission.php 